A Commentary on the misalignment of teacher education and the need for classroom behavior management skills

Nathan A. Stevenson, Ph.D.

Kent State University

Janet VanLone, Ph.D.

Bucknell University

Brian R. Barber, Ph.D.

Kent State University

[Contact Info] Please address all correspondence regarding this paper to, Nathan A. Stevenson, 405 White Hall, 150 Terrace Drive, Kent, OH 44242-0001, nsteve15@kent.edu [Conflicts of Interest] The authors have no financial conflicts of interest relevant to this work 


\begin{abstract}
Teachers' skill in fostering students' engagement and limiting disruptive behavior is important for maintaining a safe, productive, and effective learning environment. Yet, teachers lacking specific training in classroom and behavior management continue to report higher levels of stress and are more likely to leave the profession (Ingersoll et al., 2018; Zabel \& Zabel, 2002). Despite wide agreement from experts about the importance of developing classroom and behavior management skills, many teacher training programs do not require specified coursework or experiences to develop this skill set for teacher licensure or degree completion. In this article, we describe what we observe to be a disconnect between current requirements for and by teacher preparation programs, and the nature of adequate teacher training to appropriately manage and support student behavior. We argue that this disconnect currently contributes to a host of problematic outcomes observable in schools, including teacher attrition, racial disproportionality in discipline actions, and an overreliance on punitive and ineffective behavior support practices. We end our discussion with additional recommendations for improving teacher training and ensuring systems alignment.
\end{abstract}

Keywords: behavior, classroom management, teacher training, systems 


\section{A Commentary on the misalignment of teacher education and the need for classroom behavior management skills}

As the adage goes, your system is perfectly aligned to the results you get. This phrase is intended to invoke reflection and accountability for the outcomes produced by a system - any system - that is responsible for and evaluated according to expected results. In our current public education system (i.e. teacher training, classroom practice, certification, and accountability) the responsibilities are diverse, and educators are accountable for the safety and security, achievement, and even the social-emotional and physical well-being of students. The evaluation of school performance is similarly multifaceted; the accountability era has encumbered schools and teachers to prioritize the importance of some results to the detriment of others (cf. U. S. Department of Education, 2019). In such a climate, the public education system is aligned to produce some unfortunate yet predictable outcomes - exempli gratia, high dropout rates, low levels or reading proficiency, high incidence of behavior problems, and high rates of teacher attrition. It is our position that creating meaningful change related to these outcomes will require the intentional realignment of multiple educational systems working in collaboration (viz., public schooling, teacher preparation programs, and state and local education agencies, and licensure boards).

Yet, creating a sustainable and cohesive system between K-12 schools and higher education based on shared goals has proven difficult (Perna \& Armijo, 2014). K-12 schools and higher education institutions typically develop and maintain independent curricula, assessments, governance, instructional standards, and funding systems (Conley, 2013; Kirst \& Usdan, 2009; Kirst \& Venezia, 2005; Venezia et al., 2005). Each has a deeply rooted infrastructure (e.g. course offerings, personnel, decision-making processes) that may not easily be altered without 
confronting existing norms, policies, and traditions. Complete systems alignment between teacher training institutions and K-12 schools is an ideal, and it is naïve to expect that it could be accomplished in short order. Altering existing systems requires long-term change efforts that may meet considerable resistance along the way. For example, simply adding a course to university teacher training curricula would likely require elimination of an existing course or revision to multiple courses in order to make room for new content. Changing curricula is also typically a lengthy process that involves navigating university committees and processes. Furthermore, any change impacting a program leading to teacher licensure may also need approval from the state department of education.

Even if substantive changes did occur quickly, it is unlikely such changes would be helpful or sustainable. For complex educational systems, the most productive course of action is to target specific areas on which to focus collaborative efforts and solutions (Perna \& Armijo, 2014). We submit that the misalignment of teacher training and the skills teachers need in schools is most dire when considering teachers' development and effective use of classroom and behavior management skills.

Inability to manage challenging classroom behaviors contributes to a host of adverse effects including, increased teacher stress, decreased job satisfaction (Klassen \& Chiu, 2010; Landers et al., 2008; Smith \& Ingersoll, 2004; Wang et al. 2015), and negative effects on student learning (Flower et al., 2017). Conversely, teachers who effectively manage their classrooms (a) report higher levels of job satisfaction, (b) are less likely to experience burnout (Canrinus et al., 2012; Caprara et al., 2006), and (c) their students are more likely to make academic progress (Evertson \& Emmer, 1982; Sutherland \& Wehby, 2001). Inadequate skill in classroom management, by contrast, is linked to increased rates of teacher attrition (Borman \& Dowling, 
2008; Haynes, 2014; Ingersoll, 2001; Klassen \& Chiu, 2010; Landers et al., 2008; Zabel \& Zabel, 2002). Among general education teachers, nearly $40 \%$ leave teaching within the first 7 years of their career. For special education teachers, the rate jumps to $40 \%$ of teachers leaving teaching within their first three years (Hill \& Flores, 2014). Evidence also indicates insufficient classroom management training disproportionately affects the retention of teachers in high-need areas such as science and math (Ingersoll \& May, 2012). Across general education, special education, math, science, or others, the research is remarkably consistent. Difficulty with classroom management is a major contributor to teacher attrition (Freeman et al. 2014; Oliver \& Reschly, 2007, 2010; Stough, et al.,2015).

As has been noted elsewhere (cf. Buchanan, et al., 2013; Oliver \& Reschly, 2007; Stough, 2015) significant research has attested that classroom and behavior management competencies are highly influential to the persistence of new teachers (Dinkes et al., 2009). Moreover, the disruptive behavior of students is a major reason why teachers leave the profession (Ingersoll et al., 2018). The preparation and professional development of new teachers is a major contributor to these trends. Insofar as current teacher distribution patterns that indicate less qualified teachers are more prevalent in economically and socially disadvantaged classrooms (Sutcher et al., 2016), the issue of adequate preparation for effective classroom and behavior management is not only a matter of sustaining a viable workforce, it is also a matter of an inequitable capacity to support student behavior and an associated reliance on ineffective practices leading to lower rates of achievement, participation, and school completion for some students (Flower, et al., 2017).

In the remainder of this paper, we describe the impact of effective classroom behavior management on students and teachers in contemporary society and the many ways in which lack 
of training in critical classroom and behavior management skills negatively impacts individual, community, and societal goals for public education. We then provide recommendations for considering a realignment between educational systems responsible for fostering skills to address student behavior that are currently leading to less than acceptable results.

\section{Classroom and Behavior Management Revisited}

The term classroom management conjures a range of meanings. Here, we define classroom management as the set of skills, practices, and strategies teachers use in order to maintain productive and prosocial behavior in a whole-class or small group setting. Key components of classroom management include establishing behavioral expectations (e.g. positively stated rules), explicit teaching, practice, and reinforcement of classroom routines and procedures, and instructive responses to behavioral problems that reduce the likelihood of behavior problems in the future (e.g. teach alternative behaviors and avoid reinforcement of undesired behaviors). Specifically, Simonsen and colleagues (2008) have outlined five critical features of evidence-based classroom management practices, including: (a) maximize structure in your classroom; (b) post, teach, monitor, review, and reinforce a small number of positively stated expectations; (c) actively engage students in observable ways; (d) establish a continuum of strategies to acknowledge appropriate behavior; and (e) establish a continuum of strategies to respond to inappropriate behavior.

In many cases the terms classroom management and behavior management are conflated or regarded as synonyms. Though they are distinct concepts with similar goals, the skills required are quite different. What distinguishes classroom management from behavior management is an emphasis on instructional groups as opposed to individual students. Behavior management typically focuses on the identification and management of behaviors for individual 
students. This is commonly done thorough individual thoughtfully crafted behavior plans (i.e. Functional Behavior Assessments and Behavior Intervention Plans). Individual behavior management requires identification of specific target behaviors that can be shaped or replaced with a more productive or socially appropriate behavior. Classroom management generally refers to management of groups of students in an instructional setting in which prolonged periods of attention to an individual is impossible, impractical, and/or counterproductive (i.e. whole class instruction). Classroom management emphasizes prevention and response to common behavior problems that may compromise classroom instruction or disrupt the learning of peers. Examples of common behavior problems include minor off-task behaviors such as talking to peers during instruction, failure to engage in assigned tasks promptly, distracting fellow classmates, talking out of turn, and others.

\section{Quality Instruction and Classroom Management}

The link between quality instruction and effective classroom management is inextricable and reciprocal in nature. When instruction is highly engaging students are generally performing tasks that are incompatible with disruptive or off-task behaviors (Gage \& Macsuga-Gage, 2017). Engaging instruction prevents many, if not most, common behavior problems (MacSuga-Gage \& Simonsen, 2015), and the effective use of classroom management techniques enables teachers to provide engaging instruction (Martin et al., 2016; Skiba et al., 2016). In the best of circumstances effective classroom management allows the teacher to more effectively engage students in academic tasks, which in turn reduces problem behaviors resulting in a positive feedback loop that benefits students and teacher. Developing teachers' skills in both instruction and classroom management is critical (cf. Martin \& Sass, 2010), as one does not portend the other. 
In many cases, the division between instructional practices and those that are explicitly behavioral are artificial. For example, providing a high frequency of opportunities for students to speak, write, or move in response to instruction, commonly referred to as opportunities to respond (OTRs) is both a behavioral strategy and an instructional one (Haydon et al., 2009). Instructionally, OTRs are a means of engagement and interaction with the teacher and content. Engagement with instruction is near universal in its acceptance as a pillar of quality instruction. From a behavioral perspective, OTRs function as a mechanism to maintain active participation and limit instances of counterproductive behaviors.

The use of feedback is another good example. Providing specific, actionable, performance feedback enables improved academic performance by pinpointing specific actions the student can take to either avoid future errors or replicate current success. Specific feedback also serves as a mechanism for reinforcing productive behaviors. Each interaction with a student engaged in an academically productive task may reinforce the engaged behavior simply by means of attention from the teacher.

There is no denying the impact of engaging instruction on the creation of a productive learning environment. Prevention of behavior problems through quality instruction is essential. But even the most skilled teachers are likely to encounter behaviors that are disruptive, disengaged, or unproductive from time to time. Becoming an effective teacher requires high levels of skill in both effective instructional practices that prevent behavior problems and effective responsive strategies that maintain a productive learning environment over time. Teacher training programs, as a result, must arm teachers with instruction and behavioral skills they can use strategically to provide the optimal learning environment for students.

\section{Teacher Preparation for Classroom and Behavior Management}


Freeman et al. (2014) reviewed course offerings in classroom management and voluntarily submitted course materials from teacher preparation program. Only $65 \%$ of these materials demonstrated evidence of teaching evidence-based content. Though the majority of teacher education programs responding to a survey reported that they did offer instruction in classroom management strategies, such as establishing rules and creating positive climates, fewer programs reported inclusion of evidence-based classroom management strategies, such as specific strategies to increase appropriate behavior and decrease inappropriate behavior, and behavioral assessment. These finding, as well as those from a similar study by Flower et al., (2017) indicate that many pre-service teachers are not exposed to important content necessary for the success of students and teachers.

\section{Indisposition of Current Approaches to Preparation}

Deciding what skills and content to include within the practical limits of teacher training curricula has been one of the preeminent challenges of teacher education. Given the depth and breadth of skills teachers need to be successful, it is difficult to squeeze necessary coursework and field experiences into a four or five year program. Even if one considers that teacher preparation programs merely provide a foundation that will be supplemented by career-long professional development, the need to keep training programs within a reasonable cost and timeframe means university faculty must make very hard choices about what goes in, and what stays out of the curriculum. Like so many topics in education, there is no consensus regarding the essential elements of teacher training. Public education is a dynamic enterprise that requires flexibility, context specificity, and mindfulness of cultural and societal values, many of which are geographically and culturally localized. K-12 students are not a monolith, and neither are communities. They are a dynamic amalgum of individuals with various learning histories, 
dispositions, culture, goals, and values. Providing a quality educational experience that serves the needs of students within a given community requires understanding and responding to the goals and values of individuals and families within that community. It is incumbent upon teacher educators, therefore, to provide teachers with the knowledge and skills needed to best meet the needs of students, and fulfill the goals of education in a democratic society. To strive for anything less is a disservice to students and the citizenry writ large. Teacher educators have a responsibility to ensure the training they provide is well-aligned with the needs of students and teachers in the field, as well as the communities they serve. It simply makes sense, then, to shape the contributing education systems in such a way that enables the values and goals of a community to come to fruition.

Still, teacher training programs across the United States fail to provide the basic classroom management skills teachers need. As of 2015, analysis of data from National Council of for the Accreditation of Teacher Education (NCATE; Now known as the Council for the Accreditation of Educator Preparation) indicates less than $15 \%$ of teacher preparation programs require coursework in classroom management for all graduates seeking teacher licensure. This mismatch between teacher training and the needs of students and teachers is a fundamental flaw in contemporary education systems in the United States.

Experts within the overlapping fields of school reform and teacher preparation have eloquently espoused the idea that classroom management training be included as staple of all teacher training programs leading to state licensure (Dicke, et al., 2015; Simonsen, et al., 2008). To further the point, we suggest that training teachers in the principles and practices of evidencebased classroom and behavior management (within a positive behavior support framework) is a necessary first step for improving the quality of teacher training, and coordination with ongoing 
professional development efforts is essential to meet the practical and ethical demands of the profession.

Numerous researchers (Butler \& Monde-Amaya, 2016; Dicke, et al., 2015; Flower, et al., 2017; Oliver \& Reschly, 2010; Simonsen, et al., 2014) have highlighted the importance of classroom and behavior management in teacher training. To wit, a systematic review of the literature examined common elements of effective practices for preparation of pre-service teachers in classroom management (Authors, 2020). Researchers found that across the literature, multi-component interventions were most effective when it came to improving use of specific, evidence-based classroom management skills, and increasing knowledge and efficacy in effective classroom management practices. Based on their findings, the research provide guidelines for effective teacher preparation in classroom management are recommended. These include "(1) provide direct, explicit instruction in general classroom management practices and specific classroom management skills, and whenever possible, include a model or demonstration of the practice/skill, (2) provide interactive, structured, guided practice opportunities in course and field work, and whenever possible, provide scaffolded, faded support, and (3) provide immediate, specific feedback regarding pre-service teacher performance of classroom management practices/ skills." Additionally, using technology, such as simulations can further support these effective practices. Finally, teacher preparation programs should thoughtfully interweave instruction and practice opportunities throughout both coursework and field experiences.

\section{Ongoing Professional Development}

One may argue that teacher training programs are merely a starting point for building a highly competent workforce of educators. This is certainly true, as it is not practical or feasible 
for teacher candidates to develop a complete package of knowledge, skills, and experience within their collegiate teacher training programs. Professional knowledge grows with experience, mentorship, and continued participation in professional learning opportunities. Nevertheless, the development of critical instructional skills and habits aligned with the best evidence on teaching and learning is critical to the success of teachers and students. Given the high rates of teacher attrition previously mentioned, it is foolhardy to think ongoing professional development is a sufficient substitute for developing good classroom management habits at the initial stages of training.

There is very little evidence that ongoing teacher professional development substantively impacts student achievement. In a comprehensive review of professional development and student level effects in core academic areas, researchers found that out of 1,343 published studies only 132 (approx. 10\%) included actual evidence of increased student achievement in math, science, or language arts that could be, in any way attributed to teacher professional development. Of those, only 9 (less than 1\%) met the What Works Clearinghouse standards of evidence (Yoon, et al., 2007).

In-service professional development, furthermore, is unlikely to fill the void in classroom management training for practical reasons. First, teacher professional development is dependent on "second-order" change. That is, in the most effective professional development situations, teachers receive engaging and meaningful training from highly knowledgeable and experienced individuals, followed by a mechanism of in-situ support (i.e. coaching). As mentioned in the preceding paragraph, most professional development sessions measures success or failure based on the degree to which teacher behaviors change as a result of training. It is then assumed that changes in teacher behavior will yield positive changes in students' behavior. Rarely $(<10 \%)$ 
are student outcomes measured directly as a means of determining if such professional development is effective as part of empirical research. We hypothesize that the percentage of professional development agencies that measure student outcomes to determine training effectiveness is considerably lower.

Second, once individuals have developed poor classroom management practices, they can be remarkably difficult to change and sustain over time. Even amongst individuals that exhibit a change in behavior, participants often regress to prior patterns of behavior. This phenomenon is one of the most replicated findings in all of psychological science. It is critical, therefore, that teachers develop practices and habits of effective management during the earliest stages of training, and before ineffective practices become established.

\section{National, State, and Local Requirements}

The degree to which teachers receive classroom management training varies widely by institution and state. A review of the literature on current state policy and practice revealed clear gaps in the preparation requirements for pre-service teachers (Freeman et al., 2014). Despite the fact that most states require accredited teacher preparation programs to include some instruction in classroom management, there are virtually no descriptions regarding the specific content that must be included, how training should be delivered, which skills must be demonstrated, or how institutions are held accountable for providing such instruction and training. Only 28 states require programs to provide instruction in evidence-based practices. While requirements are often higher for teacher candidates enrolled in special education programs, pre-service teachers in alternative programs (i.e. emergency and alternative licensure) face lower requirements than those in traditional programs. 
Currently, the local control of education and the academic freedom afforded to university faculty combine to enable a patchwork of teacher education programs that vary greatly by institution. Findings from a study of 74 teacher education programs examining the classroom management instructional practices in teacher preparation programs indicate great variation across programs and little adherence to evidence-based practices (Flower et al., 2017). The effectiveness of training is very difficult to measure given this variability, as is the determination whether such training meets the needs of students and teachers in K-12 schools. To more effectively enact state requirements and ensure teacher candidates receive the necessary trainingly already required in 28 states, state departments of education must provide greater clarity and specificity on the content that is to be included during teacher training programs. It is our belief that states and local regulators are in a unique postion to develop a core set of principles and practices that allow for customization at the local level, while at the same time enabling consistency and alignment between teacher training and K-12 schools.

\section{Statewide Support}

The specific training and coursework necessary to be granted a teaching license greatly influences the course offerings of teacher training programs. Teacher licensure is typically controlled by state level departments of education or elected state boards. If they wish to have their graduates eligible for employment as teachers, colleges and universities will need to ensure their programs meet the minimum requirements of their respective states. As previously mentioned, slightly more than half of all states require some form of classroom management training. The specifics of how teachers will be trained, however, and the specific skills teacher candidates must acquire are generally left to the discretion of each institution of higher education. Classroom management training currently comes in innumerable forms, ranging from 
none at all, to large lectures ( $>200$ students) 3 hours per week, to close apprenticeship from experienced professionals. Training may be embedded within content area other courses, spread across multiple courses, or set as a stand-alone course within university training programs

To maximize the likelihood of successful and sustainable change in classroom management training, it is important that state licensure requirements align with the training best suited to meet the demands of children in schools. Vague and ambiguous state requirements sends the message to colleges and universities that classroom management training is nonessential. Given the pressures to limit the number of required credits, increase graduation rates, and maintain high rates of licensure and employment, the absence of specific state classroom management requirements endangers the sustainability of classroom management courses that are already subject to the whims of higher education faculty and administrators.

Given the leverage of state regulators over teacher licensure requirements, these agencies are uniquely positioned to make swift and meaningful change. State licensure requirements should include specific training in evidence-based classroom management practices that includes both coursework and field-based opportunities to practice and hone new skills. Changing licensing requirements to include specific classroom management training aligned with the best available research is a necessary step toward alignment between teacher training and the needs of students and teachers in the field. We strongly urge state agencies to work directly with teacher education programs to ensure state requirements are specific enough to meaningfully impact teacher education programs and aligned with the best available evidence and the needs of teachers and students in the field.

We recognize that top down changes from state departments rarely receive a warm and enthusiastic reception from the majority of teacher educators. Changes that result in more 
prescriptive requirements are often viewed by faculty as a threat to their instructional independence and academic freedom. It is certainly not our intent to suggest all universities must use the same curricula and deliver classroom management training in the same way. Changing state requirements to include specific classroom management training merely establishes a basic set of requirements with ample room for customization at the discretion of each institution. Moreover, the concepts of teacher certification and licensure exist to ensure all teachers have a minimum level of skill and expertise necessary for competent performance as classroom teachers. Aligning state requirements for classroom management with the needs of teachers and students serves to more fully realize the purpose of state licensure and positively impact both students and teachers.

\section{Culturally Relevant Practices}

Implementing evidence-based classroom management practices naturally leads to the formation of a positive, nurturing learning environment. This environment then serves as the foundation for culturally relevant practices and fosters respect for diverse students and needs. Without effective classroom management, historically marginalized student populations, including students with disabilities and those who are language, ethnic, and/or racial minorities are more likely to experience harsh discipline (USDOE, 2014). This includes the use of timeout and seclusion, restraint, suspension, and even expulsion. Researchers have suggested these punitive practices lead to negative short and long-term outcomes for students (Reinke \& Herman, 2002; Rumberger \& Losen, 2016; Scheuermann et al., 2016). The U.S. Department of Education (DOE) has addressed use of these harmful practices and outlined guidance for addressing school climate and discipline practices (U. S. Department of Education, 2012). This guidance has focused on marginalized populations of students. As an alternative to ineffective, harsh discipline 
practices the DOE recommends implementing multi-tiered behavioral support frameworks, such as Positive Behavioral Interventions and Supports (PBIS) that focus on the use of preventative, proactive classroom management and behavioral support strategies.

When considering how best to prepare teachers for the behavioral challenges of contemporary classrooms, it is important to ensure the practices and strategies used to maintain an orderly learning environment do not flatten the cultural identity and expression for students. That is, classroom management practices should serve to communicate the value of difference within the learning environment rather than simply train everyone to act similarly. When teaching the norms and expectations for engagement with instruction, for example, teachers must be careful not to denigrate the cultural norms and behaviors of students outside the classroom. Norms of conversation and engagement can vary widely across cultural groups. Vocabulary, pronunciation, and informal rules for conversational exchanges are important aspects of culture that must be recognized and valued. It is also important that, when teaching classroom expectations for conversation and discussion, one does not explicitly or implicitly communicate that the classroom expectations are right and others are wrong. Instead, teachers must use classroom management strategies that are culturally mindful and appropriate for the population.

\section{Classroom Management in Post-pandemic Schools}

In a move to online and blended learning environments spurred first by technological innovation, and more urgently by the global pandemic of COVID-19 it may be tempting to dismiss classroom management as either a relatively unimportant aspect of teacher training or simply a vestige of face-to-face education may longer be necessary. There are certainly some classroom management strategies, such as proximity control (Gunter, et al., 1995), which no longer apply to an educational environment in which social distancing is necessary to preserve 
the health and saftety of teachers and students. Likewise, strategies such as active supervision (Colvin, et al., 1997) are untenable, at least in asynchronous online learning environments.

We believe, though, that effective classroom management training is now more important than ever. As schools reopen after quarantine restrictions and state ordered closures, teachers and students will be returning to an environment in which face-to-face instructional time may be limited by staggered schedules, increased physical distance, and supplemented with online learning. The altered learning environment may place even more pressure on teachers to limit off task behaviors and ensure in-school instruction is engaging and productive. Teachers will need to be able to redirect students quickly and minimize disruptions. Even if schools never revert to physical conditions and arrangement of pre-pandemic learning spaces, students and teachers are likely to benefit from effective training in classroom and behavior management.

Furthermore, ensuring students abide be new safety rules and procedures will be critical for maintaining a safe learning environment. Teachers will need a full tookit of skills and strategies to ensure students practice critical preventative behaviors (i.e. social distancing, handwashing) and respond effectively when students exhibit behaviors that risk the health and safety of themselves or others (i.e. any physical touching, sharing food or objects). By leaning heavily on the tenets of effective classroom management teachers are more likely to be able to maintain an environment that is both safe and conducive to learning.

\section{Points of Caution}

It is critically important to note, we are in no way suggesting that classroom management be taught in isolation or devoid of context. We argue quite the contrary. Classroom management courses taught in college classrooms or in online courses should, ideally, be paired with a field experience in which teacher candidates have opportunities to observe, practice, and receive 
expert feedback in authentic school settings. Likewise, teachers must learn how to integrate preventative and responsive behavior management strategies and practices within effective content area instructional practices. Effective, engaging instruction begets fewer behavior problems and vice versa. Nevertheless, given the importance of classroom management, as stated above, all teacher education programs should include - at a minimum - a course focused specifically on classroom management as a core requirement in teacher education.

It is also important to note that the argument presented here must not be conflated with any argument for uniform content or pedagogy. Outside the broad goal of teaching teachers practices and strategies that are grounded in empirical research, there is little to be gained from standardizing classroom management curricula, instructional methods, textbooks, or other aspects of teaching. Flexibility in response to local contextual factors, the developing needs of teacher candidates, and the needs of schools are essential to successful training. Teacher education programs must have the professional freedom to make necessary and appropriate curricular and programmatic decisions in the best interests of students, schools, and the community.

Likewise, we recognize teacher training curricula are limited in the number of courses that are reasonable to include in training programs with limited time, resources, and personnel. Making programmatic changes requires careful navigation of policies and procedures, including those at the local and state levels. Colleges and universities have a responsibility to their students to keep credit-hour requirements at a level that does not create undo financial strain and is conducive to timely degree completion. The preponderance of research described above nevertheless suggests inclusion of classroom management as a staple of teacher education 
curricula is well worth the return on investment, particularly with regard to teacher stress, attrition, and most importantly, the impacts on student learning and social-emotional health.

Lastly, although effective classroom management may prevent many common behavior problems in group settings, it should not be viewed as a means for managing extant behavior problems that are harmful, profoundly disruptive, or persistent. Behaviors unresponsive to lowintensity strategies or those that severely compromise the safety or learning of others should be treated through a structured behavior intervention plan developed with the assistance of an individual trained to handle such issues, such as a certified applied behavior analyst or positive behavior support consultant. Teachers of students with such behaviors should seek assistance as soon as such behaviors become apparent.

\section{Conclusion}

Our aim in the preceeding commentary is not to encourage college faculty, teachers, or state administrators standardize teacher education curricula, nor dictate specific actions for communities in which we do not live. Our aim is to draw attention to a major misalignment in educational systems and provide a practical means of improving such systems for the benefit of teachers, students, and communities.

Given commonly faced challenges to instruction, behavior, and social-emotional health, teachers must be effectively trained to prevent and respond to behaviors that jeopardize the teaching and learning experience for students. Ineffective classroom management negatively impacts the learning of students, contributes to teacher attrition, and perpetuates a host of other issues (cf. Freeman et al., 2014; Oliver \& Reschly, 2007, 2010; Stough et al. 2015). To address this, the preparation of teachers must include conceptual and theoretical knowledge of student behavior and learning, as well as explicit training, feedback, and coaching in evidence-based 
classroom and behavior management practices. Such training must be contextualized within a system of teacher licensure and ongoing support that both recognizes and formalizes classroom and behavior management as key to teacher and student success. With due respect for the limits of teacher education programs, we strongly urge colleges and universities dedicated to quality teacher training to establish classroom management courses paired with meaningful, supervised field experiences as a staple element of the training of all teacher candidates. Inclusion of such training requirements would mark a major step forward in the alignment of higher education and P-12 systems, and may ultimately prove critical to the success of students and teachers in today's schools.

\section{Conflict of Interest Statement}

On behalf of all authors, the corresponding author states that there is no conflict of interest. 


\section{References}

Author, A. (2020). Pre-service teacher training in classroom management: A systematic review of the literature. Manuscript submitted for publication.

Borman, G. D., \& Dowling, N. M. (2008). Teacher attrition and retention: A meta-analytic and narrative review of the research. Review of educational research, 78(3), 367-409. http://dx.doi.org. /10.3102/0034654308321455

Buchanan, J., Prescott, A., Schuck, S., Aubusson, P., Burke, P., \& Louviere, J. (2013). Teacher Retention and Attrition: Views of Early Career Teachers. Australian Journal of Teacher Education, 38(3). http://dx.doi.org/10.14221/ajte.2013v38n3.9

Butler, A., \& Monda-Amaya, L. (2016). Preservice teachers' perceptions of challenging behavior. Teacher Education and Special Education, 39(4), 276-292. $10.1177 / 0888406416654212$

Canrinus, E. T., Helms-Lorenz, M., Beijaard, D., Buitink, J., \& Hofman, A. (2012). Selfefficacy, job satisfaction, motivation and commitment: Exploring the relationships between indicators of teachers' professional identity. European Journal of Psychology of Education, 27(1), 115-132. https://doi.org/10.1007/s10212-011-0069-2

Caprara, G. V., Barbaranelli, C., Steca, P., \& Malone, P. S. (2006). Teachers' self-efficacy beliefs as determinants of job satisfaction and students' academic achievement: A study at the school level. Journal of School Psychology, 44(6), 473-490. https://doi.org/10.1016/j.jsp.2006.09.001

Colvin, G., Sugai, G., Good, R. H. III, \& Lee, Y.-Y. (1997). Using active supervision and precorrection to improve transition behaviors in an elementary school. School Psychology Quarterly, 12(4), 344-363. https://doi.org/10.1037/h0088967

Conley, D. T. (2013). Getting ready for college, careers, and the Common Core: What every educator needs to know. John Wiley \& Sons. 
Dicke, T., Elling, J., Schmeck, A., \& Leutner, D. (2015). Reducing reality shock: The effects of classroom management skills training on beginning teachers. Teaching and Teacher Education, 48, 1-12. doi:10.1016/j.tate.2015.01.013

Dinkes, R., Kemp, J., \& Baum, K. (2009). Indicators of School Crime and Safety: 2009. NCES 2010-012/NCJ 228478. National Center for Education Statistics.

Evertson, C. M., \& Emmer, E. T. (1982). Preventive Classroom Management.

Flower, A., McKenna, J. W., \& Haring, C. D. (2017). Behavior and classroom management: Are teacher preparation programs really preparing our teachers? Preventing School Failure: Alternative Education for Children and Youth, 61(2), 163-169. https://doi.org/10.1080/1045988X.2016.1231109

Freeman, J., Simonsen, B., Briere, D. E., \& MacSuga-Gage, A. S. (2014). Pre-service teacher training in classroom management: A review of state accreditation policy and teacher preparation programs. Teacher Education and Special Education, 37(2), 106-120. https://doi.org/10.1177/0888406413507002

Gage, N. A., \& MacSuga-Gage, A. S. (2017). Salient classroom management skills: Finding the most effective skills to increase student engagement and decrease disruptions. Report on Emotional \& Behavioral Disorders in Youth, 17(1), 13.

https://www.ncbi.nlm.nih.gov/pmc/articles/PMC6345407/

Gunter, P. L., Shores, R. E., Jack, S. L., Rasmussen, S. K., \& Flowers, J. (1995). On the Move Using Teacher/Student Proximity to Improve Students’ Behavior. Teaching Exceptional Children, 28(1), 12-14. https://doi.org/10.1177/004005999502800103

Haydon, T., Borders, C., Embury, D., \& Clarke, L. (2009). Using effective instructional delivery as a class-wide management tool. Beyond Behavior, 18(2), 12-17.

Haynes, M. (2014). On the path to equity: Improving the effectiveness of beginning teachers. Alliance for Excellent Education. Retrieved from http://all4ed.org/reportsfactsheets/path-to-equity/ 
Hill, D. A., \& Flores, M. M. (2014). Modeling positive behavior interventions and supports for preservice teachers. Journal of Positive Behavior Interventions, 16(2), 93-101. https://doi.org/10.1177/1098300713478665

Ingersoll, R. M. (2001). Teacher turnover and teacher shortages: An organizational analysis. American Educational Research Journal, 38(3), 499-534 https://doi.org/10.3102/00028312038003499

Ingersoll, R. M., \& May, H. (2012). The magnitude, destinations, and determinants of mathematics and science teacher turnover. Educational Evaluation and Policy Analysis, $34(4), 435-464$.

Ingersoll, R., Merrill, L., Stuckey, D., \& Collins, G. (2018). Seven Trends: The Transformation of the Teaching Force. Updated October 2018. Consortium for Policy Research in Education.

Kirst, M. W., \& Venezia, A. (2005). From high school to college: Improving opportunities for success in postsecondary education. PsycEXTRA Dataset. http://doi.org/10.1037/e565212006-013

Kirst, M. W., \& Usdan, M. D. (2009). The historical context of the divide between K-12 and higher education. States, schools, and colleges: Policies to improve student readiness for college and strengthen coordination between schools and colleges, 5-22. http://www.highereducation.org/reports/ssc/ssc_Cha_1.pdf

Klassen, R. M., \& Chiu, M. M. (2010). Effects on teachers' self-efficacy and job satisfaction: Teacher gender, years of experience, and job stress. Journal of Educational Psychology, 102(3), 741. http://doi.org/10.1037/a0019237

Landers, E., Alter, P., \& Servilio, K. (2008). Students' challenging behavior and teachers' job satisfaction. Beyond Behavior, 18(1), 26-33. http://dx.doi.org/10.1177/1074295619900380

MacSuga-Gage, A. S., \& Simonsen, B. (2015). Examining the effects of teacher-directed opportunities to respond on student outcomes: A systematic review of the literature. 
Education and Treatment of Children, 38(2), 211-239.

http://doi.org/10.1353/etc.2015.0009

Martin, N. K., \& Sass, D. A. (2010). Construct validation of the behavior and instructional management scale. Teaching and Teacher Education, 26(5), 1124-1135. https://doi.org/10.1016/j.tate.2009.12.001

Martin, N. K., Schafer, N. J., McClowry, S., Emmer, E. T., Brekelmans, M., Mainhard, T., \& Wubbels, T. (2016). Expanding the definition of classroom management: Recurring themes and new conceptualizations. Journal of Classroom Interaction, 51(1), 31-41. https://www.jstor.org/stable/26174348

Oliver, R. M., \& Reschly, D. J. (2007). Effective Classroom Management: Teacher Preparation and Professional Development. TQ Connection Issue Paper. National comprehensive center for teacher quality. https://files.eric.ed.gov/fulltext/ED543769.pdf

Oliver, R. M., \& Reschly, D. J. (2010). Special education teacher preparation in classroom management: Implications for students with emotional and behavioral disorders. Behavioral Disorders, 35(3), 188-199. http://doi.org/10.1177/019874291003500301

Perna, L. W., \& Armijo, M. (2014). The persistence of unaligned K-12 and higher education systems: Why have statewide alignment efforts been ineffective?. The ANNALS of the American Academy of Political and Social Science, 655(1), 16-35. https://doi.org/10.1177/0002716214532776

Reinke, W. M., \& Herman, K. C. (2002). Creating school environments that deter antisocial behaviors in youth. Psychology in the Schools, 39(5), 549-559. https://doi.org/10.1002/pits.10048

Rumberger, R. W, \& Losen, D. J. (2016). The High Cost of Harsh Discipline and Its Disparate Impact. UCLA: The Civil Rights Project. Retrieved from https://escholarship.org/uc/item/85m2m6sj 
Scheuermann, B., Peterson, R., Ryan, J. B., \& Billingsley, G. (2016). Professional practice and ethical issues related to physical restraint and seclusion in schools. Journal of Disability Policy Studies, 27(2), 86-95.

Simonsen, B., MacSuga-Gage, A. S., Briere, D. E., Freeman, J., Myers, D., Scott, T. M., \& Sugai, G. (2014). Multitiered support framework for teachers classroom-management practices: Overview and case study of building the triangle for teachers. Journal of Positive Behavior Interventions, 16(3), 170-190.

https://doi.org/10.1177/1098300713484062

Simonsen, B., Fairbanks, S., Briesch, A., Myers, D., \& Sugai, G. (2008). Evidence-based practices in classroom management: Considerations for research to practice. Education and Treatment of Children, 31(3), 351-380. https://www.jstor.org/stable/42899983

Skiba, R., Ormiston, H., Martinez, S., \& Cummings, J. (2016). Teaching the social curriculum: Classroom management as behavioral instruction. Theory into practice, 55(2), 120-128. https://doi.org/10.1080/00405841.2016.1148990

Smith, T. M., \& Ingersoll, R. M. (2004). What are the effects of induction and mentoring on beginning teacher turnover?. American Educational Research Journal, 41(3), 681-714. https://doi.org/10.3102/00028312041003681

Stough, L. M., Montague, M. L., Landmark, L. J., \& Williams-Diehm, K. (2015). Persistent classroom management training needs of experienced teachers. Journal of the Scholarship of Teaching and Learning, 15(5), 36-48. https://doi.org/10.14434/josotl.v15i5.13784

Sutcher, L., Darling-Hammond, L., \& Carver-Thomas, D. (2016). A coming crisis in teaching? Teacher supply, demand, and shortages in the US. https://learningpolicyinstitute.org/product/coming-crisis-teaching-brief

Sutherland, K. S., \& Wehby, J. H. (2001). The effect of self-evaluation on teaching behavior in classrooms for students with emotional and behavioral disorders. The Journal of Special Education, 35(3), 161-171. https://doi.org/10.1177/002246690103500306 
U.S. Department of Education, Institute of Education Sciences, National Center for Education Statistics (2019). National Assessment of Educational Progress (NAEP), various years, 1990-2019 Mathematics and Reading Assessments.

U.S. Department of Education Office for Civil Rights. (2014). Civil rights data collection: Data snapshot (school discipline). Washington, D.C. https://ocrdata.ed.gov

U.S. Department of Education, Restraint and Seclusion: Resource Document, Washington, D.C., 2012. https://www2.ed.gov/policy/seclusion/restraints-and-seclusion-resources.pdf

Venezia, A., Callan, P. M., Finney, J. E., Kirst, M. W., \& Usdan, M. D. (2005). The Governance Divide: A Report on a Four-State Study on Improving College Readiness and Success. National Center Report\# 05-3. National Center for Public Policy and Higher Education. https:/files.eric.ed.gov/fulltext/ED508097.pdf

Wang, H., Hall, N. C., \& Rahimi, S. (2015). Self-efficacy and causal attributions in teachers: Effects on burnout, job satisfaction, illness, and quitting intentions. Teaching and Teacher Education, 47, 120-130. https://doi.org/10.1016/j.tate.2014.12.005

Yoon, K. S., Duncan, T., Lee, S. W. Y., Scarloss, B., \& Shapley, K. L. (2007). Reviewing the Evidence on How Teacher Professional Development Affects Student Achievement. Issues \& Answers. REL 2007-No. 033. Regional Educational Laboratory Southwest (NJ1). http://ies.ed.gov/ncee/edlabs

Zabel, R. H., \& Zabel, M. K. (2002). Burnout among special education teachers and perceptions of support. Journal of Special Education Leadership, 15(2), 67-73. 